\title{
Acolhimento na estratégia saúde da família durante a pandemia da Covid-19
}

\author{
Ilka Kassandra Pereira Belfort, Victor Catarino Costa, Sally Cristina Moutinho Monteiro
}

\section{RESUMO}

Relato de experiência cujo objetivo foi descrever a vivência da prática do acolhimento na Atenção primária de Saúde durante a pandemia COVID-19. O cenário do estudo foi - Centro de Saúde Dr. Antônio Guanaré em São Luís/MA. Foram capacitados 21 profissionais para o acolhimento da UBS. Durante o acolhimento foram disponibilizados folders, orientações familiares e conversas individuais com os usuários acerca das demandas solicitadas e informes necessários. Além disso, foram colocados à disposição em via WhatsApp acesso para materiais sobre o vírus. Sendo assim, a criação de dispositivos e estratégias de tecnologias leves de saúde permitiram o desenvolvimento de intervenções de emergência neste momento de crise. Através dessa experiência entendemos como é possível desenvolver abordagens de melhor qualidade e mais eficazes, avaliando sua possível adoção no futuro. No mais, acreditase que $o$ acolhimento desenvolvido de forma assertiva oferece uma escuta qualificada e transcorre pela eficácia no atendimento da população.

Palavras-chave: Acolhimento; Atenção Primária à Saúde; COVID-19.

\section{ABSTRACT}

Experience report whose objective was to describe the experience of welcoming practice in primary health care during a COVID-19 pandemic. The study scenario was the Dr. Antônio Guanaré Health Center in São Luís / MA. 21 professionals were trained to welcome UBS. During the reception, folders, family guidelines, and individual conversations with users were made available on the requested requests and the necessary information. Also, it was allowed to make available via WhatsApp for access to virus material. Thus, the creation of health technology devices and strategies allows the development of emergency threats at this time of crisis. Through this experience, we understand how it is possible to develop better and more difficult approaches, to evaluate their possibility of adoption in the future. No more, it is believed that the welcoming developed assertively offers a qualified experience and passed through assistance in serving the population.

Keywords: User Embracement; Primary Health Care; COVID-19.
Revista da Rede APS 2021

Publicada em: 01/04/2021

DOI:10.14295/aps.v3i1.139

Ilka Kassandra Pereira

Belfort

(Secretaria Municipal de Saúde de São Luís, MA, Brasil)

Victor Catarino Costa (Secretaria Municipal de Saúde de São Luís, MA, Brasil)

Sally Cristina Moutinho Monteiro

(Universidade Federal do Maranhão, São Luís, MA, Brasil)

Correspondência para:

Ilka Kassandra Pereira Belfort ilkabelfort@gmail.com 


\section{INTRODUÇÃO}

A doença intitulada COVID-19 é uma pandemia global emergente causada pelo coronavírus $2 \mathrm{da}$ síndrome respiratória aguda grave (SARS-CoV-2) e se originou na cidade de Wuhan na China (PERLMAN, 2020; TAN et al., 2020). Os primeiros casos tiveram origem no mercado de frutos do mar da cidade exatamente na virada do ano de 2020 (TAN et al., 2020).

Em meados de março 2020, a Organização Mundial da Saúde (OMS) declarou estado de pandemia da doença, confirmando-se mais de 8.985.016 casos e mais de 468.881 mil mortes em decorrência da infecção pelo SARS-CoV-2, até o dia 22 de junho de 2020 (ORGANIZAÇÃO PAN-AMERICANA DE SAÚDE, 2020).

A curva ascendente da epidemia fez com que muitos governos nacionais e internacionais adotassem intervenções de impacto para sociedade em geral, como estratégias de lockdown, a fim de conter a disseminação rápida da infecção de novos indivíduos e reduzir a sobrecarga social da doença e sua mortalidade. Contudo, apesar de serem necessárias, tais medidas, trouxeram uma mudança brusca e impactos negativos na vida das pessoas (PARMET; SINHA, 2020). Para além das questões sanitárias e epidemiológicas, 0 impacto da epidemia na dinâmica econômica, social, política e cultural demonstrou os limites da governança dos países e agências internacionais, evidenciando os pós e contras da globalização.

Essas mudanças seriam maiores e com mais efeitos negativos se o Sistema Único de Saúde (SUS) não comportasse uma rede de serviços que, no cotidiano, trabalha de forma comprometida e colaborativa para a diminuição das urgências e emergências em saúde.

Nesse contexto, à medida que o número de indivíduos infectados com COVID-19 continua a aumentar e os sistemas de saúde se tornam cada vez mais lotados, chegando próximo ao colapso, fica claro que a Atenção Primária a Saúde (APS) desempenhará um papel essencial nessa crise, contribuindo para a orientação, triagem, encaminhamento, monitoramento e vigilância epidemiológica dos usuários. O serviço de saúde público disponível no Brasil é um dos maiores sistemas de saúde universal do mundo, com seu eixo prioritário na rede de atenção primária a saúde, mas que apresenta problemas de subfinanciamento, gestão, provisão de profissionais e estruturação dos seus serviços (MEDEIROS, 2018). Mas, mesmo neste cenário que exige atenção e (re)estruturação, a APS brasileira, em particular, a Estratégia de Saúde da Família (ESF) tem alcançado resultados promissores, que a destacam em âmbito internacional. Há inúmeras evidências que indicam ação significativa na redução de morbimortalidade e desigualdades em saúde, o que tende a ser potencializado pela combinação com políticas de transferência de renda e proteção social (SARTI et al., 2020).

Somado aos inúmeros desafios dos profissionais e da gestão em saúde com a pandemia da COVID-19, está o acolhimento, que se constitui um dispositivo da Política Nacional de Humanização (PNH) objetivando a reorientação da atenção e da gestão no cuidado e na produção de saúde (RODRIGUES; IBANHES, 2019). O acolhimento é uma ação técnica primordial que visa à triagem na assistência centrada no protagonismo dos sujeitos e na cogestão em relação à produção conjunta do cuidado. A ESF como porta de entrada do SUS, deve praticar e fortalecer $\mathrm{o}$ acolhimento buscando a integralidade do cuidado e o bom desempenho da Rede de Atenção à Saúde (RAS). Sendo assim, este relato de experiência objetivou apresentar a experiência vivenciada na prática do acolhimento na Atenção Primária a Saúde.

\section{METODOLOGIA}

Trata-se de uma experiência vivenciada na sala de espera da Unidade Básica (UBS) de Saúde Antônio Guanaré.

O cenário do estudo foi o Centro de Saúde Dr. Antônio Guanaré que está localizado no Bairro do Coroadinho do Município de São Luís/MA, pertencente ao Distrito Coroadinho. Esta UBS 
prioriza todos os programas (saúde da criança, da mulher, do adulto e do idoso, etc.) inseridos no eixo da ESF com atenção integral, equânime e contínua. Esses programas seguem as Diretrizes da Atenção Primária do Ministério da Saúde e são desenvolvidos por uma equipe multidisciplinar composta de médicos, enfermeiros, odontólogos, técnicos de enfermagem e agentes comunitários de saúde.

A sala de recepção foi reorganizada para melhor otimização do espaço devido a necessidade (re)arranjo do fluxo de pacientes por conta da pandemia. No primeiro momento, esse de angústia pelo desconhecido, iniciou-se a capacitação dos profissionais do serviço de saúde e planejamento da escala de trabalho, com ênfase das ações na centralidade dos usuários.

A capacitação ocorreu durante uma semana (anterior a abertura do atendimento - 06 a 10 de abril de 2020) e foi direcionada aos profissionais de saúde e demais funcionários da UBS. Participaram desta capacitação 3 enfermeiros que atuam no atendimento da UBS e $1 \mathrm{da}$ gestão, 12 agentes comunitários de saúde, 1 profissional da gerência, 2 técnicos de enfermagem e 2 administrativos da recepção.

Elencou-se alguns temas considerados urgentes para as capacitações, como: biossegurança, protocolos de COVID-19, humanização no atendimento, prioridades (classificação do usuário de acordo com a gravidade de suas queixas), sinais e sintomas das síndromes gripais, bem como encaminhamentos. Além disso, foram reforçadas as questões sobre higienização pessoal, de ambientes e o uso correto de equipamentos de proteção individual (EPI).

Sabedores que os Agentes Comunitários de Saúde (ACS) possuem contato mais próximo com população e com os dispositivos sociais locais ressaltamos para os mesmos a importância de repassar informações sobre a boa higienização domiciliar/corporal, sua execução simples e corriqueira, bem como sua importância para evitar o contágio e a disseminação do COVID-19.
Além disso, foi enfatizado a necessidade de informações confiáveis sobre o binômio saúde $x$ doenças da população adstrita, para que possamos ter dados fidedignos sobre sintomatologia, casos suspeitos e confirmados, assim como um retrato mais próximo tendo um olhar na vigilância em saúde e social no sentido de diminuir as consequências negativas que uma crise sanitária como essa pode provocar.

Porém, mesmo após o período de capacitação, diariamente antes do início dos atendimentos, tem-se conversas com os responsáveis pelo acolhimento daquele turno para sanar dúvidas e (re)orientar sobre: empatia, prioridades, medidas de higiene, ações de resolutividade, humanização, orientações, encaminhamentos, entre outros.

\section{RESULTADOS E DISCUSSÃO}

Algumas medidas, foram tomadas para o "novo normal" que estava por vir, com isso, foram realizadas capacitações dos profissionais envolvidos direta e indiretamente para atendimento e acolhimento da população, que se apresentava apreensiva com tudo que estava acontecendo, e sem entender muito bem o que estaria por vir.

Foram capacitados 21 profissionais para o acolhimento da UBS para atuarem no acolhimento segundo a perspectiva da Política HumanizaSUS, buscando garantir o atendimento adequado, a comunicação assertiva e escuta qualificada dos usuários, o trabalho colaborativo, além da qualidade e resolutividade das ações.

$\mathrm{Na}$ oportunidade do acolhimento foram disponibilizados folders e conversas individuais com os usuários acerca das demandas solicitadas e informes necessários sobre a COVID-19. Além disso, foram colocados à disposição acesso a folders e panfletos sobre a doença (COVID-19), incluindo sobre sua prevenção, controle e questões relativas à saúde mental. 
Finalmente, foram disponibilizados serviços de aconselhamento via WhatsApp, mensagens de textos e telefone, feitos por profissionais de saúde inseridos e capacitados na UBS Antônio Guanaré. Estes estavam disponíveis 24 horas por dia, todos os dias da semana.

Ao início da pandemia teve-se uma baixa procura pelos serviços de saúde da UBS, isso ocorreu devido a informes divulgados na mídia sobre a não necessidade de procura dos serviços de saúde em casos leves dos sinais e sintomas da doença. Contudo, esse evento consolidou o quão é necessário o constante monitoramento e avaliação dos indicadores de saúde através da vigilância em saúde, planejando as ações para um acesso com qualidade e resolutividade, respeitando o princípio da equidade ${ }^{7}$.

Porém, após, a cada 3 dias teve-se a necessidade de monitoramento domiciliar dos usuários por apresentarem sintomas suspeitos que foram identificados pelos ACS. Todavia, ao final do primeiro mês, após a capacitação e abertura da unidade, a procura pelos serviços da UBS e seus profissionais, triplicou. Esse aumento sugere-se que foi ocasionado pelos inúmeros noticiários sobre as incertezas e desconhecimento da doença, além da morbidade e mortalidade ocasionada pela mesma noticiada a cada instante pelas mídias (televisão, rádio e internet).

Durante o acolhimento na sala de espera da UBS percebeu-se que havia muitos questionamentos e medos advindos não somente dos usuários/famílias que adentravam a UBS, mas também dos profissionais que ali estavam para o atendimento e seguimento daquele usuário.

Foram ouvidas algumas falas diárias, como exemplo, tenho medo de vir no postinho, mas não de ir às compras. Aqui tem doenças, lá não. Tenho medo porque a máscara pode não aderir bem ao rosto, ou posso ter me tocado acidentalmente com luvas sujas, ou talvez as lentes não cubram completamente meus olhos $e$ alguma coisa possa ter passado..." Essa doença não existe, tudo inventado, não vou usar máscaras, não consigo respirar..." “...medo...não consigo dormir...não consigo comer. Meu pai faleceu, tinha tuberculose, eles dizem que foi COVID, eu acho que foi tuberculose"

A cada fala/choro dita pelos usuários na sala de espera remetia a uma imensidão de pensamentos negativos, de impotência enquanto profissional de saúde no acolhimento/atendimento. O que dizer para uma família que procurava a UBS para informar que o ente querido não estava mais entre o seio familiar (foi ceifado pela COVID-19), se não fomos capacitados para comunicação de más notícias? E o que dizer e como acolher quando esse usuário era o próprio profissional de saúde lotado na UBS Antônio Guanaré?

Situações vivenciadas diariamente ao longo desses meses que permeiam a pandemia. E que trouxe novos pensamentos, novos fazeres, medos e demandas na assistência em saúde. Olhar para o outro livre de preconceitos, de fórmulas milagrosas e assistência desburocratizada foi essencial para o acolhimento de escuta qualificada. Segundo Franco, Bueno e Merhy (2019), Seixas et al. (2019) [...] o acolhimento aborda disponibilidade de tempo e compromisso para a sua realização [...], observa-se ainda que ele pode ser entendido tanto como elemento inicial do processo de trabalho em saúde, assumindo conexões que acionam as tecnologias leves, como também assumir um lugar de aplicação de diretrizes operacionais para a materialização dos princípios do SUS, em especial a integralidade, a universalidade e a equidade (CARVALHO; MERHY; SOUSA, 2019).

Dessa forma, entendemos, durante o transcorrer dos dias, a importância do profissional psicólogo no acompanhamento dos profissionais da unidade de saúde, principalmente após cada atendimento nos espaços da UBS. Profissionais capacitados e sabedores que possuem suporte técnico e emocional podem acolher melhor os usuários e suas famílias, que por muitas vezes são conhecidas da área adscrita do Coroadinho e fazem parte do convívio social rotineiro dos mesmos.

Logo, uma atenção primária forte tem uma atuação intersetorial que é importante para 
lidar socialmente com os desdobramentos de uma pandemia (CABRAL et al., 2020). Desdobramentos esses, que não são diretamente relacionados à saúde, mas que evidentemente têm repercussão sobre ela porque afetam as condições de vida da sociedade em geral. Nesse contexto, apresentase o acolhimento como um diálogo a partir de uma resposta para possível melhoria de vínculo que comumente acontecem nos serviços de saúde. Trata-se de uma técnica de conversa que fortalece laços e que pode ter lugar em qualquer atendimento e/ou encontro com os usuários (ROCHA; SPAGNUOLO, 2015). E esse, deve ser desenvolvido de maneira acolhedora, empática, ética e resolutiva.

\section{CONSIDERAÇÕES FINAIS}

Diante de todo contexto, os ACS tiveram um papel primordial para o enfretamento e reorganização do fluxo, pois os mesmos detêm o vínculo mais próximos com a comunidade assistida. Aptidões foram desenvolvidas para esse atual momento, como o uso do telefone celular, por meio de informações, muitos passaram a se comunicar em grupos, por meio de aplicativos de mensagem instantânea, dentre outros recursos.

Sem imunização ou medicamento comprovadamente eficaz, o novo coronavírus é um desafio para profissionais de saúde e cientistas que buscam a cada dia conhecer melhor sobre o vírus e o processo de adoecimento que esta causa, para assim diminuir sua mortalidade. O acolhimento é essencial nesse momento para o oferecimento de informações fidedignas e resolutividade precoce dos possíveis casos iniciais de COVID-19 tendo como primordial a excelência no primeiro atendimento.

Nesse sentido, a criação de dispositivos e estratégias de tecnologias leves de saúde permitem o desenvolvimento de intervenções de emergência em momentos de crise, como o atual. Através dessa experiência entendemos que é possível desenvolver abordagens em saúde, de baixo custo, qualidade e eficazes, e sua possível adoção neste momento ou no futuro.

No mais, acredita-se que o acolhimento desenvolvido de forma assertiva oferece uma escuta qualificada e transcorre pela eficácia no atendimento da população na Unidades Básicas de Saúde; além de nos fortalecer como estabelecimento de saúde e seres humanos. 


\section{REFERÊNCIAS}

CABRAL, E. R. de M. et al. Contribuições e desafios da atenção Primária À Saúde frente à pandemia de COVID-19. Inter American Journal of Medicine and Health, v. 3, p. 1 - 12, 2020. DOI: https://doi.org/10.31005/iajmh.v3i0.87. Disponível em: https://www.iajmh.com/iajmh/article/view/87/130. Acesso em: 12 maio 2020.

CARVALHO, M. S. de; MERHY, E. E.; SOUSA, M. F. de. Repensando as políticas de saúde no Brasil: educação permanente em saúde centrada no encontro e no saber da experiência. Interface: Comunicação, Saúde, Educação, Botucatu, v. 23, p. 190211, 2019. DOI: https://doi.org/10.1590/interface.190211. Disponível em: https://www.scielo.br/scielo.php?pid=S1414-32832019000100285\&script=sci_arttext. Acesso em: 2 maio 2010.

FRANCO, T. B.; BUENO, W. S.; MERHY, E. E. O acolhimento e os processos de trabalho em saúde: o caso de Betim, Minas Gerais, Brasil. Cadernos de Saúde Pública, Rio de Janeiro, v. 15, n. 2, p. 345-353, abr./jun. 1999. DOI: https://doi.org/10.1590/S0102-311X1999000200019. Disponível em: https://www.scielo.br/scielo.php?pid=S0102-311X1999000200019\&script=sci_abstract\&tlng=pt. Acesso em: 2 maio 2010.

MEDEIROS, J. F. D. A humanização como política pública no Sistema único de Saúde: humanizaSUS na atenção básica de Campinas-SP. Dissertação (Mestrado em Saúde Coletiva: Políticas e Gestão em Saúde Área de concentração: Política, Gestão e Planejamento) - Faculdade de Ciências Médicas, Universidade Estadual de Campinas, Campinas, $2018 . \quad$ Disponível em: http://www.repositorio.unicamp.br/bitstream/REPOSIP/332066/1/Medeiros_JessicaFariasDantas_M.pd f. Acesso em: 12 jun. 2020.

ORGANIZAÇÃO PAN-AMERICANA DE SAÚDE: Brasil. Folha informativa: COVID-19 (doença causada pelo novo coronavírus). Brasília, DF, $2020 . \quad$ Disponível em: https://www.paho.org/bra/index.php?option=com_content\&view=article\&id=6101: covid $19 \&$ Itemid=87 5. Acesso em: 20 jul. 2020.

PARMET, W. E.; SINHA, M. S. Covid-19 - the law and limits of quarantine. New England Journal of Medicine, v. 382, n. 15, p. 28, apr. 2020. DOI: 10.1056/NEJMp2004211. Disponível em: https://www.nejm.org/doi/10.1056/NEJMp2004211. Acesso em: 15 abr. 2020.

PERLMAN, S. Another decade, another coronavirus. New England Journal of Medicine, v. 382, p. 760-762, feb. 2020. DOI: 10.1056/NEJMe2001126. Disponível em: https://www.nejm.org/doi/full/10.1056/NEJMe2001126. Acesso em: 23 abr. 2020. 